\title{
Relationship Between Coronavirus-Related eHealth Literacy and COVID-19 Knowledge, Attitudes, and Practices among US Adults: Web-Based Survey Study
}

Lawrence An ${ }^{1,2}$, MD; Elizabeth Bacon ${ }^{1}, \mathrm{MPH}$; Sarah Hawley ${ }^{1,2,3}, \mathrm{PhD}$; Penny Yang ${ }^{1}, \mathrm{BSc}$; Daniel Russell ${ }^{4}, \mathrm{PhD}$; Scott Huffman ${ }^{4}$, PhD; Ken Resnicow ${ }^{1,5}, \mathrm{PhD}$

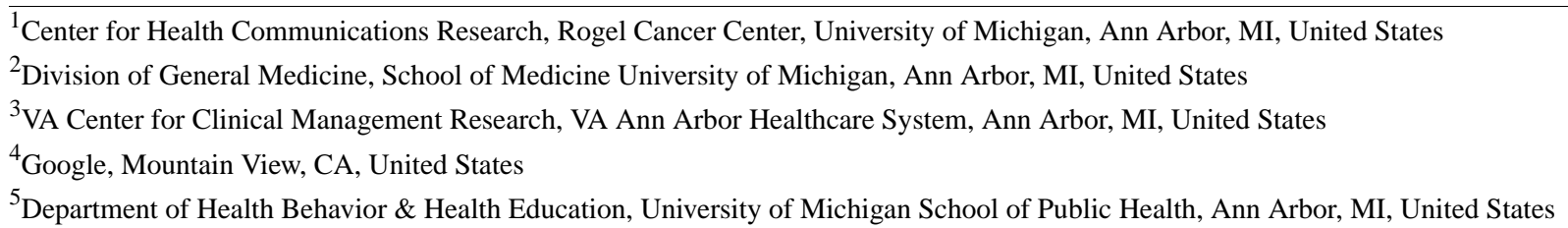

\section{Corresponding Author:}

Lawrence An, MD

Center for Health Communications Research

Rogel Cancer Center

University of Michigan

North Campus Research Complex, Building 16

2800 Plymouth Rd

Ann Arbor, MI, 48109

United States

Phone: 17347636099

Email: 1can@med.umich.edu

\section{Abstract}

Background: During a global pandemic, it is critical that the public is able to rapidly acquire new and accurate health information. The internet is a major source of health information. eHealth literacy is the ability of individuals to find, assess, and use health information available on the internet.

Objective: The goals of this study were to assess coronavirus-related eHealth literacy and examine the relationship between eHealth literacy and COVID-19-related knowledge, attitudes, and practices (KAPs).

Methods: We conducted a web-based survey of a representative sample of 1074 US adults. We adapted the 8-item eHealth Literacy Scale to develop the Coronavirus-Related eHealth Literacy Scale (CoV-eHEALS) to measure COVID-19-related knowledge, conspiracy beliefs, and adherence to protective behaviors (eg, wearing facial masks and social distancing). Our analyses identified sociodemographic associations with the participants' CoV-eHEALS scores and an association between the CoV-eHEALS measure and COVID-19 KAPs.

Results: The internal consistency of the adapted CoV-eHEALS measure was high (Cronbach $\alpha=.92)$. The mean score for the CoV-eHEALS was 29.0 (SD 6.1). A total of 29\% (306/1074) of the survey participants were classified as having low coronavirus-related eHealth literacy (CoV-eHEALS score <26). Independent associations were found between CoV-eHEALS scores and ethnicity (standardized $\beta=-.083, P=.016$ for Black participants) and education level (standardized $\beta=-.151, P=.001$ for participants with high-school education or lower). Controlling for demographic characteristics, CoV-eHEALS scores demonstrated positive independent associations with knowledge (standardized $\beta=.168, P<.001$ ) and adherence to protective behaviors (standardized $\beta=.241, P<.001$ ) and a negative association with conspiracy beliefs (standardized $\beta=-.082, P=.009$ ).

Conclusions: This study provides an estimate of coronavirus-related eHealth literacy among US adults. Our findings suggest that a substantial proportion of US adults have low coronavirus-related eHealth literacy and are thus at a greater risk of lower and less-protective COVID-19 KAPs. These findings highlight the need to assess and address eHealth literacy as part of COVID-19 control efforts. Potential strategies include improving the quality of health information about COVID-19 available on the internet, assisting or simplifying web-based search for information about COVID-19, and training to improve general or coronavirus-specific search skills. 
(J Med Internet Res 2021;23(3):e25042) doi: 10.2196/25042

\section{KEYWORDS}

internet; digital health; eHealth; eHealth literacy; coronavirus; COVID-19; knowledge; conspiracy beliefs; protective behaviors; social distancing; survey; health communication; attitude; behavior

\section{Introduction}

During a global pandemic, it is critical that members of the public are able to rapidly acquire new and accurate health information [1-4]. This includes information about the causative agent, transmission and course of the disease, as well as prevention and treatment [5,6]. It is also important to be able to avoid misinformation that might discourage protective behaviors or even encourage actions that lead to self-harm. This includes specific mistaken beliefs (eg, the new disease is no more serious than common existing infections) and also broader conspiracy theories (ie, unsubstantiated and implausible assertions that hidden forces in control of the society have created or are using the pandemic to extend their authority) that can interfere with or undermine individual or public responses to the pandemic. Research continues to identify deficits in the public's knowledge of key facts regarding the current COVID-19 pandemic, particularly among underserved groups that bear a disproportionate burden in terms of the number of COVID-19 cases and deaths [7-10]. The prevalence and negative impact of misinformation and the spread of conspiracy beliefs during the current pandemic (eg, spread of the "Plandemic" viral video) have also been increasingly recognized [6,11-14].

The internet has become a major source of health information for the public [15-19]. eHealth literacy refers to the ability of individuals to find, assess, and effectively use health information available on the internet [20]. The eHealth Literacy Scale (eHEALS) is one of the most commonly used measures to assess eHealth literacy and has been shown to be reliable and valid across a range of health conditions and populations [21-32]. eHealth literacy may be particularly important during the current pandemic because some widespread disease-control strategies (eg, social distancing) can limit in-person contact and reduce transmission of key information through these channels. Several authors have highlighted the importance of considering eHealth literacy in the response to the current global COVID-19 pandemic [1-4]. A prior study has demonstrated an association between higher receipt of information about COVID-19 available on the internet and increased engagement in personal protective behavior against COVID-19, such as handwashing, wearing facial masks, and avoiding social gatherings [33].

The goals of this study were to: (1) understand the ability of individuals to identify, assess, and effectively utilize health information about the coronavirus available on the internet and (2) determine how this ability might be associated with COVID-19-related knowledge, attitudes, and practices (KAPs). We performed a web-based survey of a nationally representative sample of US adults to achieve these goals.

\section{Methods}

\section{Measures}

For each of the following measures, specific survey items were presented to the survey respondents in random order.

\section{Coronavirus-Related eHealth Literacy}

We slightly modified items from the well-established eHEALS [20] to focus specifically on health information available on the internet about the coronavirus. The resulting 8-item measure assesses an individual's self-rated ability (answered on a 5-point Likert scale) to use the internet to find and utilize health information about the coronavirus. The specific items of this coronavirus-related eHEALS (CoV-eHEALS) were as follows:

1. I know what health resources about coronavirus are available on the internet.

2. I know where to find helpful health resources about coronavirus on the internet.

3. I know how to find helpful health resources about coronavirus on the internet.

4. I know how to use the internet to answer my questions about my health and coronavirus.

5. I know how to use the health information about coronavirus I find on the internet to help me.

6. I have the skills I need to evaluate the health resources about coronavirus I find on the internet.

7. I can tell high-quality health resources from low-quality health resources about coronavirus on the internet.

8. I feel confident in using information about coronavirus from the internet to make health decisions.

An overall CoV-eHEALS score was computed based on the sum of the scores for each item (range 8-40). The internal consistency of the CoV-eHEALS measure was 0.92, and this was not improved by the deletion of any specific item. Some prior studies have also defined cut-off points to characterize respondents as having low versus high eHealth literacy [22,27,29]. Consistent with this work, we categorized respondents, based on their total CoV-eHEALS score, as having low (score $<26$ ) or high (score $\geq 26$ ) coronavirus-related eHealth literacy.

\section{COVID-19 KAPS}

We assessed the survey respondents' COVID-19 KAPs by using the following measures.

\section{Knowledge}

We created a 7-item scale based on common key facts related to COVID-19, recognized as of May 2019 [5,6]. Each item was answered on a 5-point scale ranging from "Definitely false" to "Definitely true." The specific items of this scale were as follows: 
1. Coronavirus can be easily spread from one person to another.

2. Many thousands of people have died from coronavirus.

3. A vaccine is not yet available for the coronavirus.

4. Most people already have immunity to coronavirus.

5. Symptoms of coronavirus are always visible.

6. There are effective treatments for coronavirus that can cure most people.

7. Having coronavirus is about as dangerous as having the flu.

After reverse-coding of items 4-7, we created an overall knowledge score based on a mean of the scores for each item (range 1-5). The internal consistency of this knowledge measure was 0.78 , and this was not improved by the deletion of any specific item.

\section{Conspiracy Beliefs}

We developed a brief, 3-item scale based on prior studies on COVID-19 and other health issues [14,34]. The scale is intended to measure conspiracy beliefs regarding the coronavirus rather than a generalized conspiracy trait or worldview. Each item was answered along a 5-point continuum ranging from "Definitely false" to "Definitely true." The specific items of this scale were as follows:

1. The real truth about coronavirus is being kept from the public.

2. People in power are using coronavirus as an excuse to monitor and control the public.

3. The media is making coronavirus seem more dangerous that it really is.

We computed a mean of the response to these 3 items to create a conspiracy score (range 1-5). The internal consistency of this conspiracy measure was 0.74 , and this was not improved by the deletion of any specific item.

\section{Protective Behavior Adherence Score}

We examined the frequency of 7 self-reported behaviors practiced by the survey respondents over the past week, all of which are recommended for reducing the risk of transmitting and/or acquiring COVID-19 [35]. Each item was answered on a 5-point continuum: "Rarely or never," "Some of the time," "Most of the time," "Almost all of the time," and "All of the time." Our measure shares many topics in common to a recently described measure of COVID-19 infection prevention behaviors [36]. The specific items of this scale were as follows:

1. Avoiding touching my face.

2. Keeping my hands clean (eg, washing longer with soap and water, using hand sanitizer).

3. Keeping things clean in my home (eg, phone, refrigerator, doorknobs).

4. Staying home as much as possible.

5. Wearing a mask or face covering when I go out of the house.

6. Staying at least six feet (about 3 steps) away from people I don't live with.

7. Avoiding gatherings or groups of other people.

We computed a mean of the response to these items to create a protective behavior adherence score (range 1-5). The internal consistency of this positive protective behaviors index was 0.85 , and this was not improved by the deletion of any specific item.

\section{Demographic Characteristics}

Information on the demographics of the survey respondents, including age, gender, race or ethnicity, level of education, income, and political party affiliation, was obtained. Gender was initially assessed using 5 categories: male, female, transgender (identify as male), transgender (identify as female), and other. The responses were then collapsed into 2 categories ("identify as male" and "identify as female"). Race or ethnicity was coded as White, Black, Hispanic, multiracial, and other (which included American Indian, Asian, and other). Education was initially assessed with 10 strata, which were collapsed into 4 categories: none through high school or general education diploma, postsecondary (eg, trade school, some college, or associates), bachelor's, and advanced degree (eg, masters, doctoral or professional). Income was assessed with 9 strata, ranging from less than US $\$ 20,000$ to more than US $\$ 150,000$.

\section{Survey Administration}

The full survey assessed a range of individual and household characteristics, attitudes, and behaviors related to the COVID-19 pandemic. Surveys were completed through the Qualtrics web-based platform using a sample provided by Dynata [37]. Dynata's research panel comprises an opt-in list of over 60 million individuals globally. For this study we requested a nationally representative sample of 1000 US adults aged 18 years and above. Quotas were used to approximate national rates for age, gender, race, income, and US region. The survey was conducted as open enrollment, whereby eligible panel members who log into the Dynata website were offered a chance to participate in this survey. Participants received modest compensation (approximately US \$1) from Dynata for completing the survey.

During the last week of May 2020, a total of 2272 individuals clicked on our survey invitation link, of which 187 did not complete an age screener item or consent, and 609 were ineligible for the survey or refused consent. This yielded 1476 complete survey responses from age-eligible, consenting individuals. To ensure the quality of the respondent data, we further excluded 402 survey responses based on either of two criteria. First, we excluded 375 survey responses from individuals who completed the entire survey in less than 10 minutes (the minimum time we considered needed to complete a valid survey). The mean time for survey completion for these excluded respondents was 5.4 (SD 3.3) minutes. Second, we excluded 27 survey responses from individuals who answered all items within a 16-item block of items assessing attitudes (and perceived norms) toward the pandemic with an identical response. This is the equivalent of clicking down an entire column (eg, all "Strongly Agree" or "Disagree" responses) for all items. Because some of the 16 items in this section were worded in the positive direction (eg, Social distancing has slowed the spread of the coronavirus) and the others, in the negative direction (eg, Social distancing is not really doing much good), we considered these "response set" patterns contradictory and a sign of poor-quality survey responses. Thus, we finally considered 1074 surveys for the present analyses. 
The mean time to complete the survey was 25.3 (range 10.1-117.1) minutes for the included participants.

\section{Hypotheses}

We have two sets of hypotheses regarding the relationship between CoV-eHEALS scores and the participants' demographic characteristics and COVID-19-related KAPs.

\section{Hypothesis 1}

We expect to find significant associations between CoV-eHEALS scores and demographic characteristics. Specifically, we have the following expectations:

- Hypothesis 1a: CoV-eHEALS score will be negatively associated with age (ie, it will be lower among older individuals). This is based on several prior studies that found lower general eHEALS scores among older individuals [26,27,29,30].

- Hypothesis 1b: CoV-eHEALS score will be lower among ethnic minority groups. This is based on prior studies that have reported lower engagement with health information available on the internet or lower general eHEALS scores among minority populations $[17,19,27,30]$.

- Hypothesis 1c: CoV-eHEALS score will be positively associated with educational attainment (ie, it will be higher among those who report completing higher formal education). This is based on several prior studies that identified this relationship between educational attainment and the general eHEALS measure [23,26,27,29,30].

\section{Hypothesis 2}

We expect to find significant associations between CoV-eHEALS scores and COVID-19 KAPs. Specifically, we have the following expectations:

- Hypothesis 2a: CoV-eHEALS score will be positively associated with COVID-19-related knowledge. This is based on prior studies showing a positive association between the general eHEALS measure and disease-specific knowledge or perceived understanding and knowledge of personal health issues [29,31].

- Hypothesis 2b: CoV-eHEALS score will be negatively associated with conspiracy beliefs. Mistrust of traditional information sources (eg, government, public health agencies, and mainstream media) is a core characteristic of individuals who hold conspiracy beliefs. We believe there is likely a negative association between a person's trust in these information sources and their confidence that they can find, assess, and use health information available on the internet.

- Hypothesis 2c: CoV-eHEALS score will be positively associated with adherence to behaviors that protect from COVID-19. This is based on prior studies showing more positive health behaviors (eg, healthy lifestyle and engagement in cancer screening) among individuals with higher general eHEALS scores [32,38].

\section{Statistical Procedures}

For hypothesis 1, we examined the relationship between demographic variables and the CoV-eHEALS score. Age and income (represented as 9 income strata) were examined as continuous variables. Gender, ethnicity, and educational attainment were examined as categorical variables. We first examined these associations separately using Pearson's correlation to examine the association between CoV-eHEALS score and continuous variables (eg, age and income) and analysis of variance to examine the association between CoV-eHEALS score and categorical variables (eg, gender, ethnicity, and educational attainment). We then examined the independent association between demographic variables and CoV-eHEALS score by using a linear regression model with CoV-eHEALS score as the dependent variable and demographic characteristics as the independent variables (with dummy coding of gender, ethnicity, and education).

For hypothesis 2, we examined the association between CoV-eHEALS score and COVID-19 knowledge, conspiracy beliefs, and protective behaviors. We performed multivariate analysis of variance (MANOVA) to simultaneously assess the relationship between these three dependent variables (scores for knowledge, conspiracy belief, and protective behavior adherence) and our main variable of interest (ie, low vs high CoV-eHEALS scores), while controlling for demographic characteristics as covariates (with age and income as continuous variables and dummy coding for gender, ethnicity, and education). To further illustrate the relationship between CoV-eHEALS scores and COVID-19 KAPs, we created simplified composite variables to represent each KAP measures. For knowledge, we computed a sum of the total number of knowledge items answered correctly (ie, answered "Definitely true" or "Probably true" for knowledge items 1-3 and "Definitely false" or "Probably false" for knowledge items 4-7) by each respondent (range 0-7). For conspiracy beliefs, we computed a sum of the total number of conspiracy items rejected (ie, answered "Definitely false" or "Probably false") by each respondent (range 0-3). For protective behaviors, we computed a sum of the total number of behaviors for which the respondent reported routine engagement (eg, answered "Always" or "Almost Always"). We then compared the distribution of these compositive variables for respondents classified as having low versus high CoV-eHEALS scores by using chi-square tests to assess statistical significance.

All analyses for this study were performed using SPSS software (version 25; IBM Corp).

\section{Ethical Review}

This survey study was reviewed and judged to be exempt (survey without identifying information) by the University of Michigan's institutional review board.

\section{Results}

The demographic characteristics of the study participants and their CoV-eHEALS and COVID-19 KAP scores are shown in Table 1. The sample comprised 55.6\% (575/1074) female, $69.9 \%$ (723/1074) White, 8.1\% (84/1074) Black, 9.2\% (95/1074) Hispanic, and $6.3 \%(65 / 1074)$ multiracial participants. Their mean age was 47.3 (SD 17.1) years. Their mean CoV-eHEALS score was 29.0 (SD 6.1), and their mean scores for the COVID-19 KAP measures were as follows: knowledge 3.8 (SD 
0.8 ), conspiracy beliefs 2.9 (SD 1.1), and protective behaviors index 3.9 (SD 0.9).

Results of the analyses related to hypothesis 1 (ie, Associations between CoV-eHEALS score and demographic characteristics) are shown in Tables 2 and 3. Using bivariate comparison, we found a significant association between the CoV-eHEALS score and income and educational attainment (Table 2). The correlation between CoV-eHEALS score and income was positive $(r=0.087, P=.005)$ indicating individuals with higher income have higher coronavirus-related eHealth literacy. The direction of the relationship between CoV-eHEALS score and education was similar-individuals with higher educational attainment reported higher CoV-eHEALS scores. Results from a multivariate liner regression model are shown in Table 3. In this model, there are independent associations between CoV-eHEALS scores and ethnicity and educational attainment. The CoV-eHEALS score was lower for Black participants (standardized $\beta=-.083, P=.02$ ) than for White participants (the reference group). The CoV-eHEALS score was lower among participants who completed education only up to a high-school degree (standardized $\beta=-.151, P=.001$ ) than among those with advanced degrees (the reference group). In the regression model, the association with income was no longer significant. The association between CoV-eHEALS score and age was not significant in either the bivariate $(r=0.009, P=.79)$ or multivariate (standardized $\beta=-.038, P=.29$ ) analysis.

Table 1. Characteristics of study participants $(\mathrm{N}=1074)$ and their mean scores for various study measures.

\begin{tabular}{|c|c|}
\hline Variable & Value, $\mathrm{n}(\%)$ \\
\hline \multicolumn{2}{|l|}{ Age (years), n (\%) } \\
\hline $18-35$ & $304(29.5)$ \\
\hline $36-50$ & $263(25.6)$ \\
\hline $51-65$ & 277 (26.9) \\
\hline$\geq 65$ & $185(18)$ \\
\hline \multicolumn{2}{|l|}{ Income (US \$), n (\%) } \\
\hline$<30,000$ & $291(28.1)$ \\
\hline $30,000-74,999$ & $397(38.4)$ \\
\hline$\geq 75,000$ & $346(33.5)$ \\
\hline \multicolumn{2}{|l|}{ Gender, n (\%) } \\
\hline Male & $459(44.4)$ \\
\hline Female & $575(55.6)$ \\
\hline \multicolumn{2}{|l|}{ Race or ethnicity, n (\%) } \\
\hline White & $723(69.9)$ \\
\hline Black & $84(8.1)$ \\
\hline Hispanic & $95(9.2)$ \\
\hline Multiracial & $65(6.3)$ \\
\hline Other & $67(6.5)$ \\
\hline \multicolumn{2}{|l|}{ Education, $\mathrm{n}(\%)$} \\
\hline Up to high school or GED ${ }^{a}$ & $225(21.8)$ \\
\hline Postsecondary (eg, trade school, some college, or associates) & $326(31.6)$ \\
\hline Bachelor's degree & $310(30)$ \\
\hline Advanced degree (eg, Masters, Doctoral or Professional) & $172(16.7)$ \\
\hline \multicolumn{2}{|l|}{ Scores, mean (SD) } \\
\hline Coronavirus-related eHealth Literacy Scale (range 8-40) & $29.0(6.1)$ \\
\hline Knowledge (range 1-5) & $3.8(0.8)$ \\
\hline Conspiracy beliefs (range 1-5) & $2.9(1.1)$ \\
\hline Positive behavior adherence (range 1-5) & $3.9(0.9)$ \\
\hline
\end{tabular}

${ }^{\mathrm{a}}$ GED: Tests of General Educational Development. 
Table 2. Bivariate association between demographic characteristics and coronavirus-related eHealth literacy.

\begin{tabular}{lll}
\hline Variable & eHealth literacy score, mean (SD) $P$ value \\
\hline Gender & & $29.2(6.3)$ \\
Male & $28.9(5.9)$ \\
Female & \\
Ethnicity & $29.1(6.0)$ \\
White & $27.6(5.7)$ \\
Black & $28.9(6.3)$ \\
Multiracial & $29.4(5.9)$ \\
Hispanic & $29.3(7.1)$ \\
Other & \\
Education & $27.6(6.6)$ \\
Up to high school or GED & $28.8(6.0)$ \\
Postsecondary (eg, trade school, some college, or associates) & $29.9(5.7)$ \\
Bachelor's degree & $30.0(5.5)$ \\
Advanced degree (eg, Masters, Doctoral or Professional) & \\
\hline
\end{tabular}

${ }^{\mathrm{a}}$ GED: Tests of General Educational Development.

Table 3. Independent association between demographic characteristics and coronavirus-related eHealth literacy.

\begin{tabular}{|c|c|c|}
\hline Variable & Standardized $\beta$ coefficient & $P$ value \\
\hline Age (continuous) & -.038 & .29 \\
\hline Income (continuous, 9 strata) & .023 & .21 \\
\hline \multicolumn{3}{|l|}{ Gender } \\
\hline Male & $\operatorname{Ref}^{\mathrm{a}}$ & \\
\hline Female & -.003 & .92 \\
\hline \multicolumn{3}{|l|}{ Ethnicity } \\
\hline White & Ref & \\
\hline Black & -.083 & $.02^{\mathrm{b}}$ \\
\hline Multiracial & -.018 & 60 \\
\hline Hispanic & -.006 & .86 \\
\hline Other & -.014 & .68 \\
\hline \multicolumn{3}{|l|}{ Education } \\
\hline Up to high school or GED ${ }^{c}$ & -.151 & $.001^{\mathrm{b}}$ \\
\hline Postsecondary (eg, trade school, some college, or associates) & -.079 & .09 \\
\hline Bachelor's & -.007 & .87 \\
\hline Advanced degree (eg, Masters, Doctoral or Professional) & Ref & \\
\hline
\end{tabular}

${ }^{\mathrm{a}}$ Ref: reference value.

${ }^{\mathrm{b}}$ Italicized values indicate statistical significance.

${ }^{\mathrm{c}}$ GED: Tests of General Educational Development.

Results of the analyses related to hypothesis 2 (ie, association between CoV-eHEALS and COVID-19 KAP scores) are shown in Table 4. Among our respondents, 29\% (306/1074) were classified as having low coronavirus-related eHealth literacy (ie, total CoV-eHEALS score <26). Results from the MANOVA model show a significant association between CoV-eHEALS score and all three (COVID-19 knowledge, conspiracy beliefs, and adherence to protective behaviors) dependent variables $\left(F_{3,1013}=20.89, P<.001\right.$; Wilks $\Lambda=0.94$, partial $\left.\eta^{2}=0.058\right)$. When adjusting for sociodemographic differences, respondents with 
higher (vs lower) CoV-eHEALS scores had higher mean scores for knowledge and protective behaviors adherence and a lower mean score for conspiracy beliefs.

The nature of the relationship between CoV-eHEALS and COVID-19 KAP scores is further illustrated in Figures 1-3. Figure 1 compares the number of knowledge items answered correctly by respondents with low versus high CoV-eHEALS scores. For those with low CoV-eHEALS scores, nearly $33 \%$ (99/305) correctly answered 2 or fewer knowledge items, and less than $10 \%$ (27/305) correctly answered all 7 items. For those with high CoV-eHEALS scores, less than 20\% (88/742) correctly answered 2 or fewer knowledge items and nearly $25 \%$ (175/742) correctly answered all 7 items. The difference in the distribution of the number of correct answers on these 7 knowledge items was statistically significant $(P<.001)$.

Figure 2 compares the number of rejected conspiracy items (ie, participants who assessed the conspiracy item as "Definitely False" or "Probably False") for participants with low versus high CoV-eHEALS scores. For those with low CoV-eHEALS scores, approximately $50 \%$ (153/305) did not reject any of these items, whereas only $8 \%(25 / 305)$ of them rejected all 3 items. For those with high CoV-eHEALS scores, 35\% (261/742) did not reject any of these items, whereas $21 \%$ (158/742) rejected all 3 items. The difference in the distribution of the number of rejected conspiracy items was statistically significant $(P<.001)$.

Figure 3 compares the number of protective behaviors routinely reported by the participants (ie, "Always" or "Almost Always" engaging in this practice) with low versus high CoV-eHEALS scores. For those with low CoV-eHEALS scores, nearly $30 \%$ $(85 / 305)$ reported engaging in 2 or fewer behaviors, and a similar proportion of the participants $(107 / 305,35 \%)$ reported routine practice of 6 or all 7 of the protective behaviors. For those with high CoV-eHEALS scores, about 15\% (109/742) of the participants reported engaging in 2 or fewer behaviors, whereas just over 50\% (487/742) reported routine practice of 6 or all 7 of the protective behaviors. The difference in the distribution of the number of routine protective behaviors was statistically significant $(P<.001)$.

Table 4. COVID-19 knowledge, conspiracy beliefs, and protective behaviors for respondents with low and high coronavirus-related eHealth literacy.

\begin{tabular}{|c|c|c|c|}
\hline \multirow[t]{2}{*}{ CoV-eHEALS ${ }^{\mathrm{a}}$ score } & \multicolumn{3}{|c|}{ Estimated mean score ${ }^{\mathrm{b}}(\mathrm{SE})$} \\
\hline & Knowledge & Conspiracy beliefs & Protective behaviors \\
\hline Low score $(n=298)$ & $3.6(0.040)$ & $3.0(0.064)$ & $3.6(0.049)$ \\
\hline High score $(\mathrm{n}=729)$ & $3.9(0.025)$ & $2.8(0.040)$ & $4.0(0.031)$ \\
\hline$P$ value & $<.001$ & .03 & $<.001$ \\
\hline
\end{tabular}

${ }^{\mathrm{a} C o V-e H E A L S}$ : coronavirus-related eHealth literacy scale.

${ }^{\mathrm{b}}$ Estimated means adjusted for age, income, gender, ethnicity, and education level. Overall multivariate analysis of variance model; Box M=53.35; $\mathrm{F}=8.86 ; P<.001$. 
Figure 1. Number of correct knowledge items by coronavirus-related eHealth literacy.

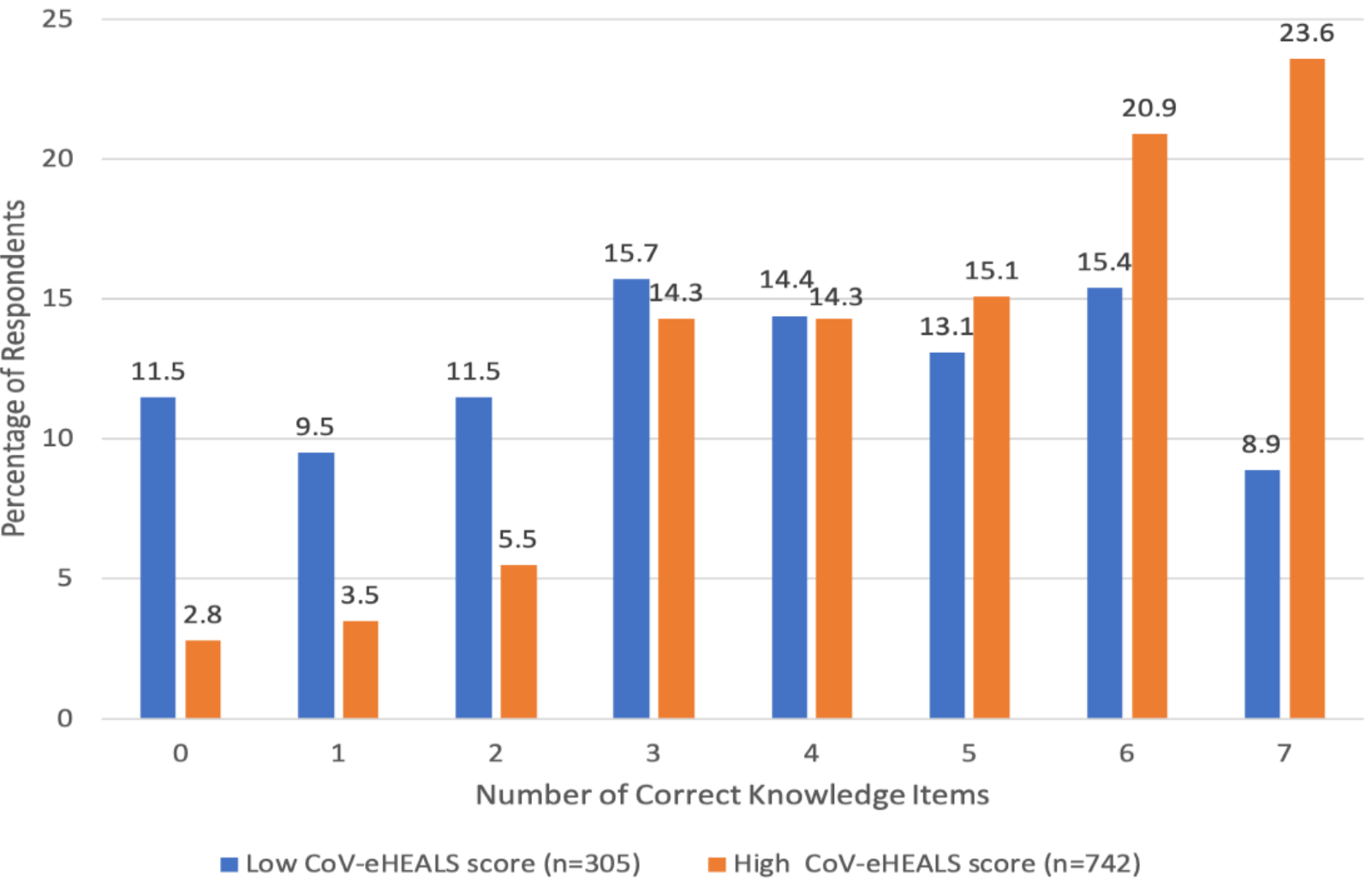

Figure 2. Number of rejected conspiracy items by coronavirus-related eHealth literacy.

$$
60
$$

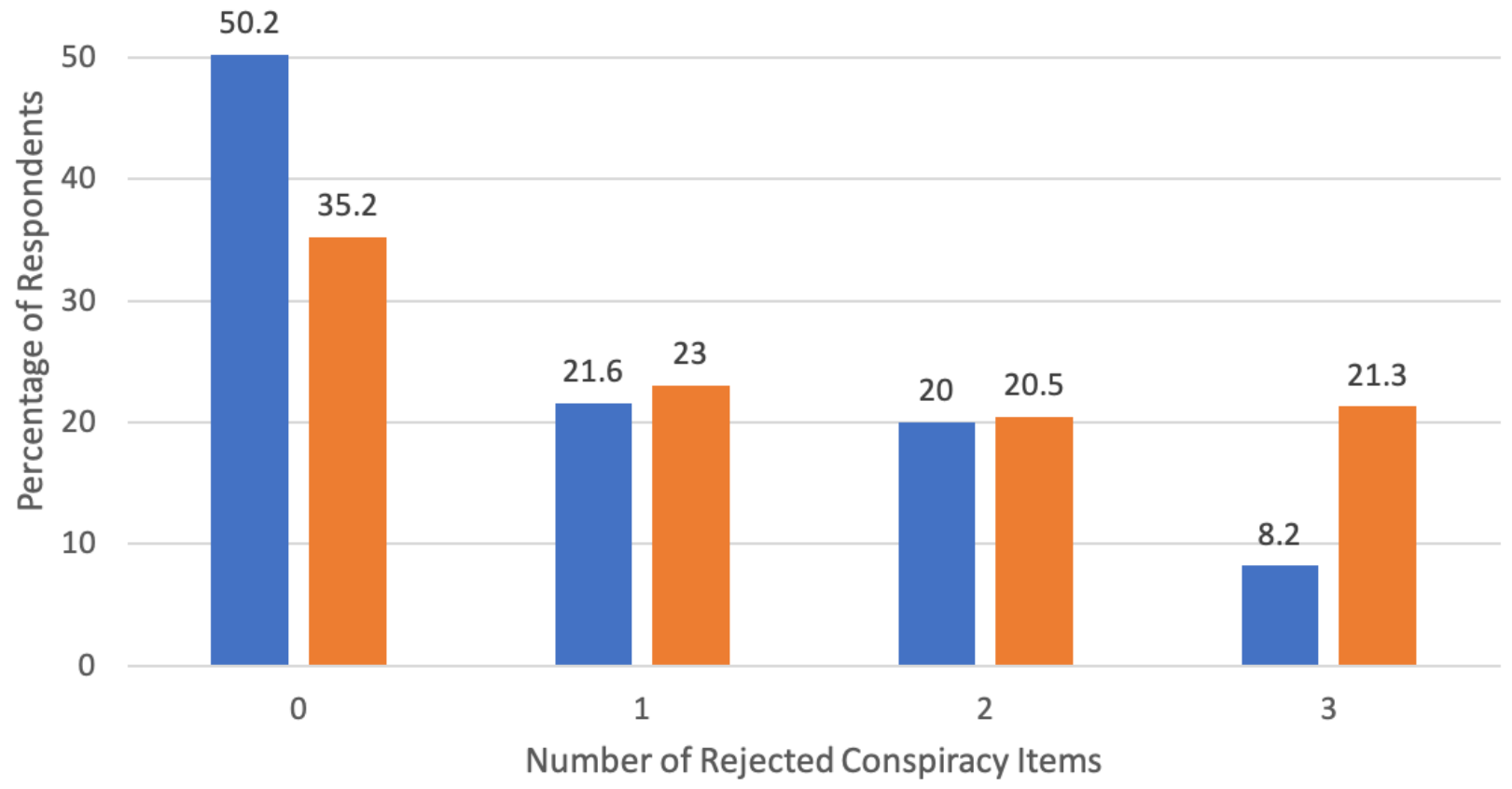

- Low CoV-eHEALS score $(n=305) \quad$ High CoV-eHEALS score $(n=742)$ 
Figure 3. Number of routine protective behaviors by coronavirus-related eHealth literacy.

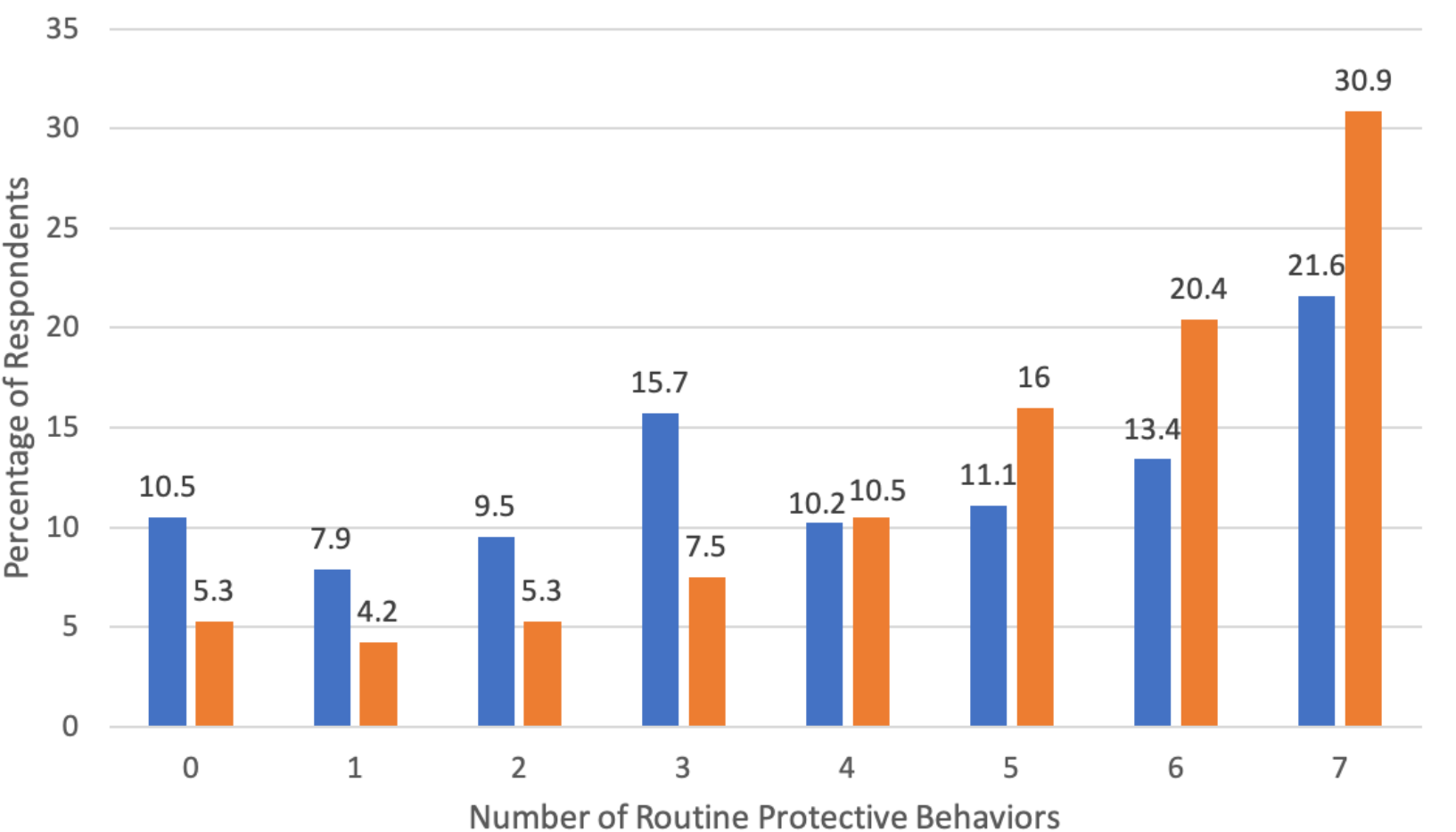

- Low CoV-eHEALS score $(n=305)$

- High CoV-eHEALS score $(n=742)$

\section{Discussion}

The principal findings of the study show a clear and consistent association between higher coronavirus-related eHealth literacy and greater knowledge, lower conspiracy beliefs, and greater engagement in protective behaviors. The mean CoV-eHEALS score used in this study was similar to those used for the general eHEALS in several population samples [23,26,27]; it was somewhat higher than that reported among some disease-specific groups (eg, cardiovascular disease, lung cancer, patients with HIV) [22,24,39]. It is possible that widespread public attention, media coverage (including content available on the internet), and concerted effort of major public health organizations to disseminate health information on the internet (eg, World Health Organization and the Centers for Disease Control) during the current pandemic contributed to this finding.

It is important to acknowledge that we administered a modified version of the eHEALS measure that was specific to information about coronavirus (ie, CoV-eHEALS). Although we recognize that this is not typical practice for evaluation of eHealth literacy, we believe this was appropriate given the critical need to assess and understand the ability of individuals and the public to find, assess, and use information available on the internet that is specific to the coronavirus during the current COVID-19 pandemic. The findings we report for this CoV-eHEALS measure are consistent with those recently reported by other teams that administered the general eHEALS measure as part of pandemic-related studies. For instance, a study by Do et al [40] of health care workers in Vietnam reported a significant positive association between participants' general eHEALS score and their self-reported adherence to occupational infection prevention and control measures. In a national web-based survey of internet users in China, $\mathrm{Li}$ and Liu [41] found a significant association between the general eHEALS measure and self-reported practice of protective behaviors against COVID-19 [41]. Future work could examine the relation between CoV-eHEALS and general eHEALS measures and COVID-19-related KAPs.

The results of this study largely support our first set of hypotheses regarding the association between CoV-eHEALS scores and demographic characteristics. Multivariate analyses showed that Black participants had lower CoV-eHEALS scores than White participants (hypothesis 1b). This finding is consistent with some prior studies that have found low general eHEALS scores and a low frequency of seeking health information on the internet among ethnic minority groups $[15,17,19,27]$. The finding of lower CoV-eHEALS scores among Black participants is of particular concern given the recognized disparities in the impact of COVID-19 on minority groups. Moreover, our finding of lower CoV-eHEALS scores among those with lower educational attainment (hypothesis 1c) is consistent with the same association observed in multiple previous studies using the general eHEALS measure $[23,26,27,29,30]$. When considered along with the finding of lower CoV-eHEALS scores among Black respondents, this finding reinforces the continued need to address COVID-19-related health disparities that place an undue burden on underserved and disadvantaged groups. Contrary to our original hypothesis $1 \mathrm{a}$, we did not find an association between the participants' CoV-eHEALS scores and age. This finding is in contrast with a number of prior studies that have identified more advanced age as a predictor of lower general eHEALS 
scores. The lack of a decrease in CoV-eHEALS score among older participants is somewhat reassuring, particularly given that older adults are at a greater risk of serious illness or death due to COVID-19.

Our study findings also consistently support our second set of hypotheses regarding the association between coronavirus-related eHealth literacy and COVID-19 KAPs. Our analyses showed a significant association in the expected directions between the CoV-eHEALS measure and COVID-19 knowledge, conspiracy beliefs, and engagement in protective behaviors. In considering these findings, it is important to recognize that self-efficacy is a central concept underlying the development of the general eHEALS and, consequently, also for this adapted CoV-eHEALS measure. Although the assessment of self-efficacy is a critical aspect of many major theories of health behavior, it is also recognized that individuals commonly overestimate their abilities to perform more complex tasks [42-45]. For the general eHEALS measure, studies examining the association between self-reported eHealth literacy and the actual performance of functional measures of internet skills have reported variable results. Van Der Vaart and colleagues [28] noted that, in a small sample of patients with rheumatic disease, an individual's eHEALS score was not consistently related to their actual performance of internet skills. In contrast, Neter and Brainin [46] found a positive, if modest, association between the self-reported general eHEALS measure and observed performance on health-related internet tasks. The nature of the relationship observed between our CoV-eHEALS measure and knowledge provide further insights into this issue. The overall positive and independent association between the CoV-eHEALS and knowledge scores lends support to the validity of the eHEALS approach. At the same time, specific findings also suggest that individuals may overestimate their abilities to some degree. Among those with high CoV-eHEALS scores (ie, high confidence in their own ability to find, assess, and use information about coronavirus on the internet), only about 1 in 4 participants was able to correctly answer all 7 items on our COVID-19 knowledge scale.

The relationship observed between the CoV-eHEALS measure and conspiracy beliefs also warrants further discussion. For our study participants, the mean score on the conspiracy beliefs scale was 2.9 , which indicates that, on average, our sample was "unsure" about the truth or falsehood of these statements. Although differences in the wording of questions and format preclude direct comparisons, other studies have reported high rates of endorsement of COVID-19 conspiracy beliefs [47,48]. Our finding of greater rejection of conspiracy beliefs among those with higher CoV-eHEALS scores is consistent with the work of Richtering and colleagues [22] who found a positive association between the eHEALS score and specific facets of a general health literacy measure, including the ability to perform "critical appraisal" of information available on the internet. Although the negative association between CoV-eHEALS and conspiracy scale scores observed in our study is encouraging, it is important to recognize that even among respondents who could be considered as having higher CoV-eHEALS scores (ie, total score $\geq 26$ ), fewer than half of the participants clearly rejected two or more of the conspiracy items. One study, involving a national survey in Poland, actually reported greater acceptance of conspiracy beliefs among individuals with higher general eHealth literacy [49]. In considering the relationship between CoV-eHEALS scores or general eHEALS scores and these beliefs, it is important to recognize the complex interplay of factors that influence conspiracy thinking such as underlying social orientation (eg, individualist vs collectivist), perception of power or powerlessness, ideology or political affiliation, and media consumption $[48,50]$. All these factors highlight the importance of considering a broader framework for managing the COVID-19 infodemic. Eysenbach [4] recently presented an "information cake" model that includes building eHealth literacy (and general scientific literacy) along with information monitoring, encouraging knowledge refinement and information quality management, and accurate and timely knowledge translation as the four pillars of effective infodemic management.

In the body of published work on the eHEALS measure, relatively few studies have reported on the relationship between eHEALS scores and specific health behaviors or health outcomes. Neter and colleagues [51] recently reviewed this topic and concluded that although there are some positive associations, additional study on this topic is needed. In the Neter review [51], the most consistent associations seemed to be between eHEALS and health behaviors. For example, Mitsutake and colleagues reported in separate studies the finding of positive association between scores on the general eHEALS measure and health-promoting behaviors (eg, physical activity, healthy eating) and also colorectal cancer screening practice $[32,38]$. We found that compared to individuals with low CoV-eHEALS scores, those with high CoV-eHEALS scores reported engaging in routine practice of one additional protective behavior (eg, mask wearing, social distancing). These observed relationships are both statistically significant and meaningful from a personal and public health standpoint. Our finding of a positive association between the CoV-eHEALS score and engagement in protective behaviors contributes to our understanding of the eHealth literacy and provides further evidence of the relationship between measures of eHealth literacy (eg, general eHEALS or our CoV-eHEALS) and actual health behaviors and practices.

There are several limitations to consider when interpreting our study findings. First, the results reported here are from a single cross-sectional survey, and thus, we cannot make claims regarding causation. For example, although we did find a negative association between CoV-eHEALS scores and conspiracy beliefs, we cannot be certain whether a higher CoV-eHEALS score led to reduced acceptance of these beliefs or whether a predisposition to conspiracy thinking led to lower CoV-eHEALS scores. Second, it is important to acknowledge that the CoV-eHEALS and COVID-19 KAP measures are based on self-report. The need for further study of the relationship between self-reported eHEALS measures and actual performance has been discussed above. Associations between trajectories of self-reported protective behaviors and COVID-19 cases supports the validity of these self-report measures; however, the precise relationship between self-reported and 
actual behavior (eg, difference between behavior that is reported to occur "some of the time" vs "almost all of the time") requires additional study [52]. Third, this survey was conducted during a single, brief time period in one specific country relatively soon after the onset of the COVID-19 pandemic. Further work will be needed to determine how CoV-eHEALS scores may vary across different countries and how this might change over time. Fourth, it is important to note that this survey was performed using a web-based survey format. Although the rates of internet access in the United States are quite high in general and characteristics of our study sample were similar to that of the general US population, the administration of a web-based survey could certainly bias the sample toward individuals with greater familiarity with technology and the internet. Computer and internet use are well-recognized predictors of eHEALS, which we did not specifically assess in this study [22,23,27,30]. As such, our estimate of $29 \%$ of the US adult population having low CoV-eHEALS scores should likely be considered a lower bound for this estimate.

Despite these limitations, there are some potentially important implications related to our study findings. We found that although the overall level of coronavirus-related eHealth literacy in this study was relatively high, there still remains a substantial proportion of the US adult population that has low coronavirus-related eHealth literacy; this population might thus be considered at higher risk of negative COVID-19 KAPs. Recent studies assessing the quality of health information available on the internet about COVID-19 have found inconsistent coverage of key public health recommendations with a majority of websites having moderate-to-low quality scores [53,54]. These authors identified substantial opportunities to improve the clarity of presentation of critical health information and argued that broader implementation and adherence to quality standards for presentation of COVID-19-related information available on the internet could be helpful in terms of improving public health literacy on this topic. It is important to note that some major search engines have taken specific steps to improve search simplicity and delivery of high-quality COVID-19-related health information. For example, Google has a dedicated landing page for COVID-19-related information that is displayed following general searches about coronavirus or COVID-19. This landing page highlights key topics (eg, disease trends; access to testing; and health information on symptoms, prevention, and treatments) with summaries of key facts and direct links leading to high-quality information sources. Finally, it is important to recognize that searching for information on the internet can be a complicated and challenging process [55]. Despite the capabilities of modern search engines, people are more effective in finding accurate information if they possess some basic skills in how to find and use information on the web (eg, knowing to "click through" to view the actual website instead of relying upon websites summaries, checking timeliness and quality of information sources, and cross-checking different information sources) [56]. Deficits in such search skills are common in the general population; nevertheless, prior work shows that through web-based training, people can develop these skills and improve their abilities to find high-quality and accurate information on the internet.

Given the consistent associations between CoV-eHEALS scores and COVID-19 KAPs, there may be some benefit in teaching such search skills in general or specifically in terms of searches for COVID-19-related information. In the future, it could be important to assess and track coronavirus-related eHealth literacy at the individual and population levels. Identifying and addressing low coronavirus-related eHealth literacy could prove helpful in improving COVID-19-related knowledge, attitudes, and practices, thereby reducing future illness and deaths during this pandemic.

\section{Acknowledgments}

This work was supported by National Cancer Institute Grant P30CA046592-29-S4 and a Google Focus award (to LA).

\section{Conflicts of Interest}

None declared.

\section{References}

1. Brørs G, Norman C, Norekvål TM. Accelerated importance of eHealth literacy in the COVID-19 outbreak and beyond. Eur J Cardiovasc Nurs 2020 Aug;19(6):458-461 [FREE Full text] [doi: 10.1177/1474515120941307] [Medline: 32667217]

2. Chong Y, Cheng H, Chan H, Chien W, Wong S. COVID-19 pandemic, infodemic and the role of eHealth literacy. Int J Nurs Stud 2020 Aug;108:103644 [FREE Full text] [doi: 10.1016/j.ijnurstu.2020.103644] [Medline: 32447127]

3. Sentell T, Vamos S, Okan O. Interdisciplinary perspectives on health literacy research around the world: more important than ever in a time of COVID-19. Int J Environ Res Public Health 2020 Apr 26;17(9):3010 [FREE Full text] [doi: 10.3390/ijerph17093010] [Medline: 32357457]

4. Eysenbach G. How to fight an infodemic: the four pillars of infodemic management. J Med Internet Res 2020 Jun 29;22(6):e21820 [FREE Full text] [doi: 10.2196/21820] [Medline: 32589589]

5. Coronavirus disease (COVID-19) pandemic. World Health Organization. URL: https://www.who.int/emergencies/diseases/ novel-coronavirus-2019 [accessed 2020-10-06]

6. Coronavirus Disease 2019 (COVID-19). Center for Disease Control and Prevention. URL: https://www.cdc.gov/coronavirus/ 2019-ncov/index.html [accessed 2020-10-06] 
7. Clements JM. Knowledge and behaviors toward COVID-19 among US residents during the early days of the pandemic: cross-sectional online questionnaire. JMIR Public Health Surveill 2020 May 08;6(2):e19161 [FREE Full text] [doi: 10.2196/19161] [Medline: $\underline{32369759]}$

8. McFadden S, Malik A, Aguolu O, Willebrand K, Omer S. Perceptions of the adult US population regarding the novel coronavirus outbreak. PLoS One 2020;15(4):e0231808 [FREE Full text] [doi: 10.1371/journal.pone.0231808] [Medline: $\underline{32302370]}$

9. Alobuia W, Dalva-Baird N, Forrester J, Bendavid E, Bhattacharya J, Kebebew E. Racial disparities in knowledge, attitudes and practices related to COVID-19 in the USA. J Public Health (Oxf) 2020 Aug 18;42(3):470-478 [FREE Full text] [doi: 10.1093/pubmed/fdaa069] [Medline: 32490519]

10. Block R, Berg A, Lennon RP, Miller EL, Nunez-Smith M. African American adherence to COVID-19 public health recommendations. Health Lit Res Pract 2020 Aug 06;4(3):e166-e170 [FREE Full text] [doi: 10.3928/24748307-20200707-01] [Medline: 32926172]

11. Cinelli M, Quattrociocchi W, Galeazzi A, Valensise CM, Brugnoli E, Schmidt AL, et al. The COVID-19 social media infodemic. Sci Rep 2020 Oct 06;10(1):16598 [FREE Full text] [doi: 10.1038/s41598-020-73510-5] [Medline: 33024152]

12. Tangcharoensathien V, Calleja N, Nguyen T, Purnat T, D'Agostino M, Garcia-Saiso S, et al. Framework for managing the COVID-19 infodemic: methods and results of an online, crowdsourced WHO technical consultation. J Med Internet Res 2020 Jun 26;22(6):e19659 [FREE Full text] [doi: 10.2196/19659] [Medline: 32558655]

13. Frenkel S, Decker B, Alba D. How the 'Plandemic' Movie and Its Falsehoods Spread Widely Online. The New York Times. URL: https://www.nytimes.com/2020/05/20/technology/plandemic-movie-youtube-facebook-coronavirus.html

14. Freeman D, Waite F, Rosebrock L, Petit A, Causier C, East A, et al. Coronavirus conspiracy beliefs, mistrust, and compliance with government guidelines in England. Psychol Med 2020 May 21:1-13 [FREE Full text] [doi: 10.1017/S0033291720001890] [Medline: 32436485]

15. Rice R. Influences, usage, and outcomes of Internet health information searching: multivariate results from the Pew surveys. Int J Med Inform 2006 Jan;75(1):8-28. [doi: 10.1016/j.ijmedinf.2005.07.032] [Medline: 16125453]

16. Powell J, Inglis N, Ronnie J, Large S. The characteristics and motivations of online health information seekers: cross-sectional survey and qualitative interview study. J Med Internet Res 2011 Feb 23;13(1):e20 [FREE Full text] [doi: 10.2196/jmir.1600] [Medline: 21345783]

17. Bangerter L, Griffin J, Harden K, Rutten L. Health information-seeking behaviors of family caregivers: analysis of the Health Information National Trends Survey. JMIR Aging 2019 Jan 14;2(1):e11237 [FREE Full text] [doi: 10.2196/11237] [Medline: 31518309]

18. Kontos E, Blake K, Chou W, Prestin A. Predictors of eHealth usage: insights on the digital divide from the Health Information National Trends Survey 2012. J Med Internet Res 2014 Jul 16;16(7):e172 [FREE Full text] [doi: 10.2196/jmir.3117] [Medline: 25048379]

19. Sherman L, Patterson M, Tomar A, Wigfall L. Use of digital health information for health information seeking among men living with chronic disease: data from the Health Information National Trends Survey. Am J Mens Health 2020;14(1):1557988320901377 [FREE Full text] [doi: 10.1177/1557988320901377] [Medline: 31973642 ]

20. Norman C, Skinner H. eHEALS: The eHealth Literacy Scale. J Med Internet Res 2006 Nov 14;8(4):e27 [FREE Full text] [doi: 10.2196/jmir.8.4.e27] [Medline: 17213046]

21. Paige S, Krieger J, Stellefson M, Alber J. eHealth literacy in chronic disease patients: An item response theory analysis of the eHealth literacy scale (eHEALS). Patient Educ Couns 2017 Feb;100(2):320-326 [FREE Full text] [doi:

10.1016/j.pec.2016.09.008] [Medline: 27658660]

22. Richtering S, Hyun K, Neubeck L, Coorey G, Chalmers J, Usherwood T, et al. eHealth literacy: predictors in a population with moderate-to-high cardiovascular risk. JMIR Hum Factors 2017 Jan 27;4(1):e4 [FREE Full text] [doi: 10.2196/humanfactors.6217] [Medline: 28130203]

23. Chung S, Nahm E. Testing reliability and validity of the eHealth Literacy Scale (eHEALS) for older adults recruited online. Comput Inform Nurs 2015 Apr;33(4):150-156 [FREE Full text] [doi: 10.1097/CIN.0000000000000146] [Medline: 25783223]

24. Milne RA, Puts MTE, Papadakos J, Le LW, Milne VC, Hope AJ, et al. Predictors of high eHealth literacy in primary lung cancer survivors. J Cancer Educ 2015 Dec;30(4):685-692. [doi: 10.1007/s13187-014-0744-5] [Medline: 25355524]

25. Nguyen J, Moorhouse M, Curbow B, Christie J, Walsh-Childers K, Islam S. Construct validity of the eHealth Literacy Scale (eHEALS) among two adult populations: a Rasch analysis. JMIR Public Health Surveill 2016 May 20;2(1):e24 [FREE Full text] [doi: 10.2196/publichealth.4967] [Medline: 27244771]

26. Tennant B, Stellefson M, Dodd V, Chaney B, Chaney D, Paige S, et al. eHealth literacy and Web 2.0 health information seeking behaviors among baby boomers and older adults. J Med Internet Res 2015 Mar 17;17(3):e70 [FREE Full text] [doi: 10.2196/jmir.3992] [Medline: 25783036]

27. Choi NG, Dinitto DM. The digital divide among low-income homebound older adults: internet use patterns, eHealth literacy, and attitudes toward computer/Internet use. J Med Internet Res 2013 May 02;15(5):e93 [FREE Full text] [doi: 10.2196/jmir.2645] [Medline: 23639979] 
28. van der Vaart R, van Deursen AJ, Drossaert CH, Taal E, van Dijk JA, van de Laar MA. Does the eHealth Literacy Scale (eHEALS) measure what it intends to measure? Validation of a Dutch version of the eHEALS in two adult populations. J Med Internet Res 2011 Nov 09;13(4):e86 [FREE Full text] [doi: 10.2196/jmir.1840] [Medline: 22071338]

29. Neter E, Brainin E. eHealth literacy: extending the digital divide to the realm of health information. J Med Internet Res 2012 Jan 27;14(1):e19 [FREE Full text] [doi: 10.2196/jmir.1619] [Medline: 22357448]

30. Chesser A, Burke A, Reyes J, Rohrberg T. Navigating the digital divide: A systematic review of eHealth literacy in underserved populations in the United States. Inform Health Soc Care 2016;41(1):1-19. [doi: 10.3109/17538157.2014.948171] [Medline: 25710808]

31. Stellefson ML, Shuster JJ, Chaney BH, Paige SR, Alber JM, Chaney JD, et al. Web-based health information seeking and eHealth literacy among patients living with chronic obstructive pulmonary disease (COPD). Health Commun 2018 Dec;33(12):1410-1424 [FREE Full text] [doi: 10.1080/10410236.2017.1353868] [Medline: 28872905]

32. Mitsutake S, Shibata A, Ishii K, Oka K. Association of eHealth literacy with colorectal cancer knowledge and screening practice among internet users in Japan. J Med Internet Res 2012 Nov 13;14(6):e153 [FREE Full text] [doi: 10.2196/jmir.1927] [Medline: 23149453]

33. Li S, Feng B, Liao W, Pan W. Internet use, risk awareness, and demographic characteristics associated with engagement in preventive behaviors and testing: cross-sectional survey on COVID-19 in the United States. J Med Internet Res 2020 Jun 16;22(6):e19782 [FREE Full text] [doi: 10.2196/19782] [Medline: 32501801]

34. van Prooijen JW, van Vugt M. Conspiracy theories: evolved functions and psychological mechanisms. Perspect Psychol Sci 2018 Nov;13(6):770-788 [FREE Full text] [doi: 10.1177/1745691618774270] [Medline: 30231213]

35. Centers for Disease Control and Prevention - COVID-19. URL: https://www.cdc.gov/coronavirus/2019-ncov/ prevent-getting-sick/prevention.html [accessed 2021-02-24]

36. Toussaint L, Cheadle A, Fox J, Williams D. Clean and contain: initial development of a measure of infection prevention behaviors during the COVID-19 pandemic. Ann Behav Med 2020 Sep 01;54(9):619-625 [FREE Full text] [doi: 10.1093/abm/kaaa064] [Medline: $\underline{32856691]}$

37. Dynata - The Data Platform for [richer] insights. URL: https://www.dynata.com [accessed 2021-02-25]

38. Mitsutake S, Shibata A, Ishii K, Oka K. Associations of eHealth literacy with health behavior among adult internet users. J Med Internet Res 2016 Jul 18;18(7):e192 [FREE Full text] [doi: 10.2196/jmir.5413] [Medline: 27432783]

39. Robinson C, Graham J. Perceived Internet health literacy of HIV-positive people through the provision of a computer and Internet health education intervention. Health Info Libr J 2010 Dec;27(4):295-303 [FREE Full text] [doi: 10.1111/j.1471-1842.2010.00898.x] [Medline: 21050372]

40. Do B, Tran T, Phan D, Nguyen HC, Nguyen TTP, Nguyen HC, et al. Health literacy, eHealth literacy, adherence to infection prevention and control procedures, lifestyle changes, and suspected COVID-19 symptoms among health care workers during lockdown: online survey. J Med Internet Res 2020 Nov 12;22(11):e22894 [FREE Full text] [doi: 10.2196/22894] [Medline: 33122164]

41. Li X, Liu Q. Social media use, eHealth literacy, disease knowledge, and preventive behaviors in the COVID-19 pandemic: cross-sectional study on Chinese netizens. J Med Internet Res 2020 Oct 09;22(10):e19684 [FREE Full text] [doi: 10.2196/19684] [Medline: 33006940]

42. Bandura A. A social cognitive theory of personality. In: Pervin L, John O, editors. Handbook of personality (2nd ed.). New York, NY: Guilford Publications; 1999:154-196.

43. Cane J, O'Connor D, Michie S. Validation of the theoretical domains framework for use in behaviour change and implementation research. Implement Sci 2012 Apr 24;7:37 [FREE Full text] [doi: 10.1186/1748-5908-7-37] [Medline: 22530986]

44. Moores T, Chang J. Self-efficacy, overconfidence, and the negative effect on subsequent performance: A field study. Information \& Management 2009 Mar;46(2):69-76. [doi: 10.1016/j.im.2008.11.006]

45. Weinberg B. A model of overconfidence. Pacific Economic Review 2009 Nov;14(4):502-515. [doi: 10.1111/j.1468-0106.2009.00466.x]

46. Neter E, Brainin E. Perceived and performed eHealth literacy: survey and simulated performance test. JMIR Hum Factors 2017 Jan 17;4(1):e2 [FREE Full text] [doi: 10.2196/humanfactors.6523] [Medline: 28096068]

47. Earnshaw V, Eaton L, Kalichman S, Brousseau N, Hill E, Fox A. COVID-19 conspiracy beliefs, health behaviors, and policy support. Transl Behav Med 2020 Oct 08;10(4):850-856 [FREE Full text] [doi: 10.1093/tbm/ibaa090] [Medline: $\underline{32910819]}$

48. Romer D, Jamieson K. Conspiracy theories as barriers to controlling the spread of COVID-19 in the U.S. Soc Sci Med 2020 Oct;263:113356 [FREE Full text] [doi: 10.1016/j.socscimed.2020.113356] [Medline: 32967786$]$

49. Duplaga M. The determinants of conspiracy beliefs related to the COVID-19 pandemic in a nationally representative sample of internet users. Int J Environ Res Public Health 2020 Oct 26;17(21):7818 [FREE Full text] [doi: 10.3390/ijerph17217818] [Medline: 33114542]

50. Biddlestone M, Green R, Douglas K. Cultural orientation, power, belief in conspiracy theories, and intentions to reduce the spread of COVID-19. Br J Soc Psychol 2020 Jul;59(3):663-673 [FREE Full text] [doi: 10.1111/bjso.12397] [Medline: 32592420] 
51. Neter E, Brainin E. Association between health literacy, eHealth literacy, and health outcomes among patients with long-term conditions. European Psychologist 2019;24(1):68-81. [doi: 10.1027/1016-9040/a000350]

52. Lazer L, Santillana M, Perlis R, Quintana A, Ognyanova K, Green J, et al. A 50-State COVID-19 Survey: Report \#26: Trajectory of COVID-19-Related Behaviors. The COVID States Project. 2020 Nov. URL: https://kateto.net/covid19/ COVID19\%20CONSORTIUM\%20REPORT\%2026\%20BEHAVIORS\%20NOV\%202020.pdf [accessed 2021-02-24]

53. Hernández-García I, Giménez-Júlvez T. Assessment of health information about COVID-19 prevention on the internet: infodemiological study. JMIR Public Health Surveill 2020 Apr 01;6(2):e18717 [FREE Full text] [doi: 10.2196/18717] [Medline: 32217507]

54. Jayasinghe R, Ranasinghe S, Jayarajah U, Seneviratne S. Quality of online information for the general public on COVID-19. Patient Educ Couns 2020 Aug 07:2594-2597 [FREE Full text] [doi: 10.1016/j.pec.2020.08.001] [Medline: 32800422]

55. Russell D. The Joy of Search - A Google Insider's Guide to Going Beyond the Basics. Cambridge, MA: MIT Press; Sep 2019.

56. Russell D, Callegaro M. How to Be a Better Web Searcher: Secrets from Google Scientists. Scientific American. 2019 Mar 26. URL: https://blogs.scientificamerican.com/observations/how-to-be-a-better-web-searcher-secrets-from-google-scientists/ [accessed 2021-02-24]

\section{Abbreviations \\ CoV-eHEALS: Coronavirus-Related eHealth Literacy Scale \\ eHEALS: eHealth Literacy Scale \\ KAP: knowledge, attitude, and practice \\ MANOVA: multivariate analysis of variance}

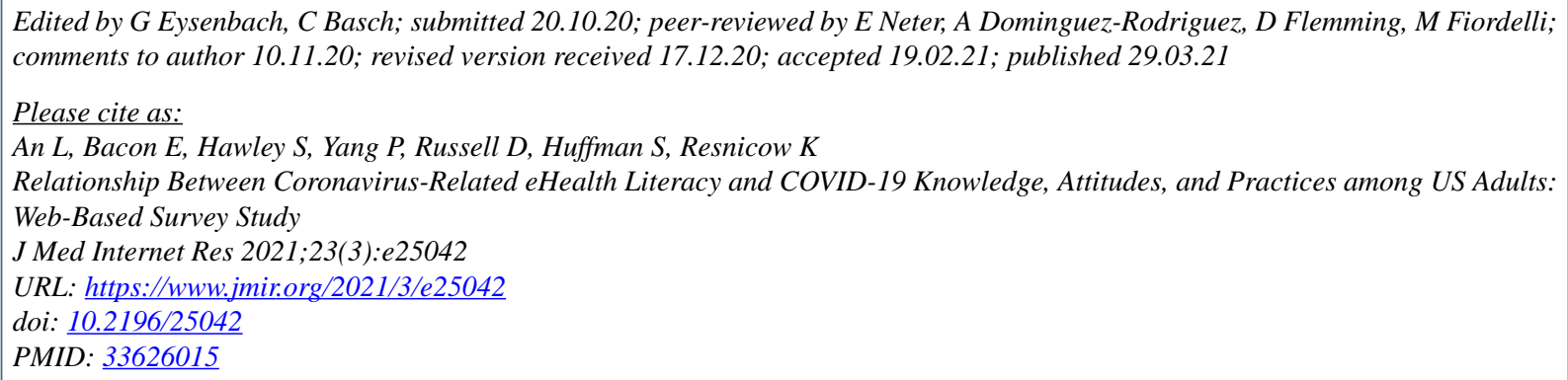

CLawrence An, Elizabeth Bacon, Sarah Hawley, Penny Yang, Daniel Russell, Scott Huffman, Ken Resnicow. Originally published in the Journal of Medical Internet Research (http://www.jmir.org), 29.03.2021. This is an open-access article distributed under the terms of the Creative Commons Attribution License (https://creativecommons.org/licenses/by/4.0/), which permits unrestricted use, distribution, and reproduction in any medium, provided the original work, first published in the Journal of Medical Internet Research, is properly cited. The complete bibliographic information, a link to the original publication on http://www.jmir.org/, as well as this copyright and license information must be included. 